\title{
PERAWATAN OBSTRUKSI SALURAN AKAR MENGGUNAKAN EDTA PADA GIGI PASKA RESTORASI AMALGAM
}

\author{
Ilma Yudistian \\ Bagian Konservasi Gigi, Fakultas Kedokteran Gigi, Universitas Mahasaraswati, Denpasar \\ Email: Ilma141288@gmail.com
}

\begin{abstract}
Root canal calsification can occur due to prolonged trauma, aging, or restorations with pressure on the teeth for a long time, and causes root canal obstructed. The purpose of this case report to evaluate the results of root canal treatment with obstructed root canal post amalgam restoration, continue with unimetrix post and PFM crown. Thirty three years old female patient has come to dental clinic to treat her left mandibular molar tooth that have big amalgam restoration in the occlusal and tooth fracture at lingual side, but there was no pain when he came. Clinical examination on tooth 36 is necrosis pulpa. Radiographs showed radiopaque area from occlusal until pulp chamber floor and no periapical lesions were found. Rewalling lingual wall was done before the procedure of multivisit root canal treatment with EDTA, that consists of three obstructed root canal. Preparation and insertion of tapered self threading dowel (unimetrix, Dentsply) and build up core with cement resin at once. Core preparation were done for PFM jacket crown, and then mold with irreversible hydrocolloid for maxilla and double impression material for the mandible. PFM jacket crown was cemented using resin cement. The evaluation after six months, there were no complaints of pain and good marginal adaptation of restoration has performed. Selection cases and the right diagnosis with treatment procedures and adequate restoration, root canal treatment can be effective and durable.
\end{abstract}

Keywords: obstructed canal, root canal treatment, EDTA

\section{PENDAHULUAN}

Kalsifikasi saluran akar dapat terjadi baik pada gigi anterior maupun posterior dengan perbandingan yang sama. Ada beberapa penyebab saluran akar terkalsifikasi, diantaranya karena proses penuaan, trauma yang berkepanjangan, infeksi kronis, gigi non vital yang belum dirawat saluran akar dalam waktu yang lama, karies gigi, restorasi yang memberi tekanan pada gigi dalam waktu yang lama, resesi gingiva ${ }^{1}$.

Proses kalsifikasi pada umumnya terdapat pada bagian koronal saluran akar, maka dari itu, apabila pada saat negosiasi saluran akar dapat melewati 1/3 koronal, selanjutnya akan lebih mudah untuk mencapai daerah apikal dengan menggunakan file ataupun reamer, dan terkadang perlu penggunaan gel EDTA atau EDTA solution disertai irigasi dengan $\mathrm{NaOCl}$ untuk melunakkan dentin pada saluran kar $^{2}$.

Bahan kelasi sudah dikenal dalam dunia endodontik sebagai bahan yang dapat membantu preparasi saluran akar sempit dan saluran akar terkalsifikasi. Bahan Ethylenediaminetetraacetic acid (EDTA) cair dianggap dapat melunakkan dentin pada saluran akar secara kimiawi dan melarutkan smear layer, serta meningkatkan permeabilitas dentin ${ }^{2}$.

Pada mulanya, bahan kelasi digunakan digunakan sebagai cairan irigasi pada saat preparasi saluran akar, kemudian pada tahun 1969, Stewart, dkk. memperkenalkan RC-Prep yang dikenal sebagai bahan kelasi tipe pasta terbaik. Meskipun efektifitas EDTA untuk melunakkan dentin baik jenis pasta maupun liquid masih dipertanyakan, penggunaan bahan kelasi saat preparasi saluran akar tetap dianjurkan, terutama pada kasus saluran akar sempit dan terkalsifikasi ${ }^{1}$.

\section{TUJUAN}

Laporan kasus ini dibuat untuk mengevaluasi hasil perawatan saluran akar pada elemen 36 yang terkalsifikasi paska restorasi amalgam. Kalsifikasi terdapat pada bagian koronal dari saluran akar distal, mesiobukal, dan mesiolingual. Selain itu, laporan kasus ini dibuat untuk mengetahui efektifitas dari EDTA baik tipe liquid maupun pasta untuk membantu mengatasi kalsifikasi pada saluran akar.

\section{KASUS \& TATALAKSANA KASUS}

Pasien perempuan usia 33 tahun datang ke klinik ingin memeriksakan gigi belakang kiri bawahnya yang merasa gigi nya patah setelah menggigit makanan keras. Pasien merasa nyeri ketika gigi yang patah tersebut digerakkan dengan lidah, jika tidak, pasien merasa tidak ada rasa nyeri. Kurang lebih 20 tahun yang lalu gigi tersebut pernah di tambal. Pada pemeriksaan intraoral terlihat restorasi amalgam pada elemen 36, dan fraktur mahkota pada bagian distolingual. Tes vitalitas menggunakan chlor etil didapatkan hasil negatif yang menunjukkan bahwa gigi telah nekrosis. Pada pemeriksaan radiograf terlihat area radiopak dari area oklusal gigi sampai dengan dasar kamar pulpa. Tidak terdapat area radiolusen pada bagian periapikal gigi 36 .

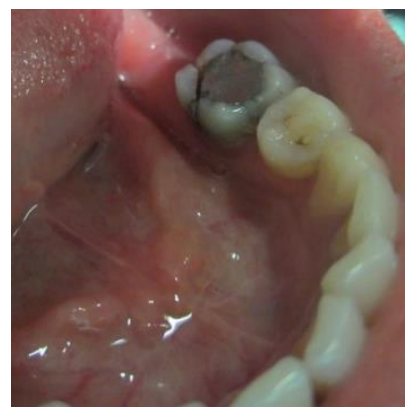

Gambar 1. Foto klinis gigi 36, terdapat restorasi amalgam dan fraktur mahkota bagian distolingual 


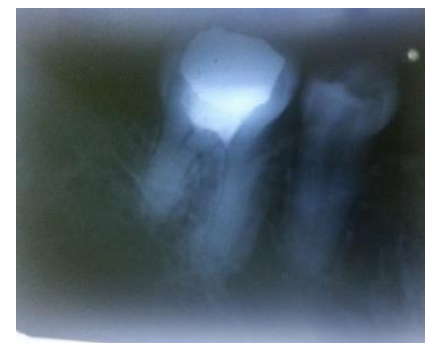

Gambar 2. Radiograf elemen 36. Tampak area radiopak dari mahkota sampai dengan dasar kamar pulpa. Tidak ada lesi pada bagian periapikal.

Pada kunjungan pertama, dilakukan pemeriksaan subjektif, objektif dan radiograf. Restorasi amalagam yang ada dibongkar termasuk base pada dasar kavitas, dan fragmen mahkota yang fraktur diambil. Kemudian dilakukan rewalling pada bagian distolingual sebelum dilanjutkan dengan perawatan saluran akar. Setelah dilakukan cavity entrance, ditemukan 3 saluran akar, yaitu saluran akar distal, mesiobukal, dan mesiolingual.

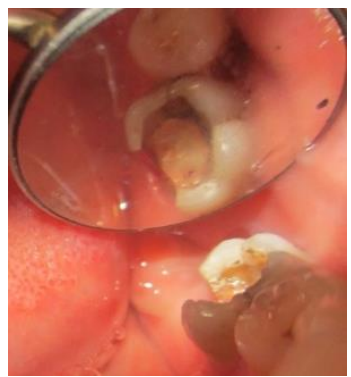

Gambar 3. Foto klinis elemen 36 setelah restorasi amalgam di hilangkan.

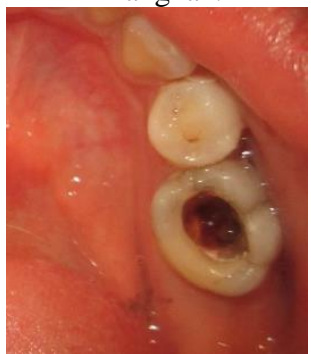

Gambar 4. Foto klinis elemen 36 setelah dilakukan rewalling

Ketiga saluran akar diketahui terdapat sumbatan pada bagian koronal, sehingga pada saat negosiasi saluran akar, file tidak dapat mencapai ujung apikal. Negosiasi saluran akar dilakukan dengan menggunakan K-file C+ \#6 dengan bantuan aplikasi pasta EDTA dikombinasikan dengan irigasi menggunakan liquid EDTA. Setelah dua kali kunjungan, akhirnya file dapat masuk ke dalam saluran akar sesuai dengan panjang kerja.

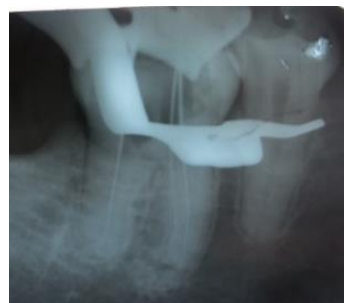

Gambar 5. Konfirmasi panjang kerja dengan x-ray
Perawatan saluran akar dilakukan dengan tehnik crown down menggunakan file ProTaper Universal hand use sampai ukuran F3 pada saluran akar distal, F2 pada saluran akar mesiobukal dan mesiolingual. Irigasi menggunaka $\mathrm{NaOCl} 2,5 \%$, Chlorhexidine 2\%, dan EDTA solution Pada kunjungan ketiga, dilakukan pengisian saluran akar menggunakan sealer berbahan dasar resin (Topseal, Dentsply).

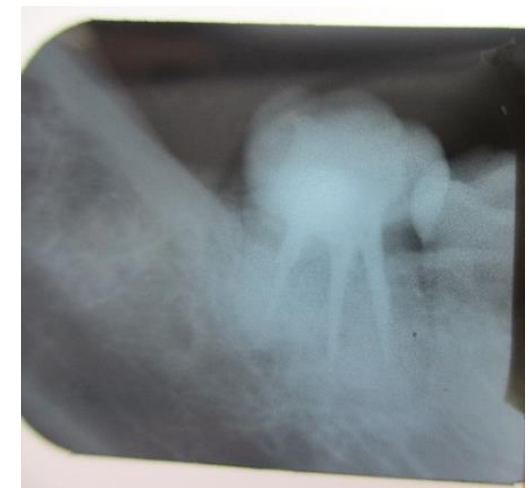

Gambar 6. Hasil pengisial saluran akar elemen 36

Pada kunjungan ke-4 (satu minggu setelah obturasi) dilakukan insersi pasak tapered selfthreading dowel (Unimet, Dentsply). Diawali dengan tracing saluran pasak menggunakan template pasak dan x-ray gigi 36 untuk menentukan besar pasak yang akan digunakan. Dari hasil tracing diketahui besar pasak yang akan digunakan adalah \#2 pada saluran akar distal dan \#1 pada saluran akar mesiobukal. Preparasi pasak diawali dengan pengambilan gutta percha dengan Peeso reamer, setelah itu dilanjutkan dengan trial post menggunakan x-ray sebelum dilakukan sementasi. Sementasi pasak dilakukan menggunakan semen resin dual cure (built it FR, Pentron) sekaligus dilakukan built up core. Setelah insersi pasak selesai, dilanjutkan dengan preparasi crown dan pencetakan dengan tehnik double impression sebagai persiapan restorasi akhir dengan porceain fused to metal crown.

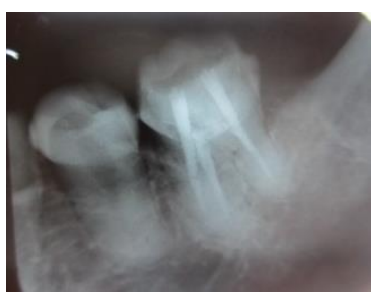

Gambar 7. Radiograf hasil insersi pasak.

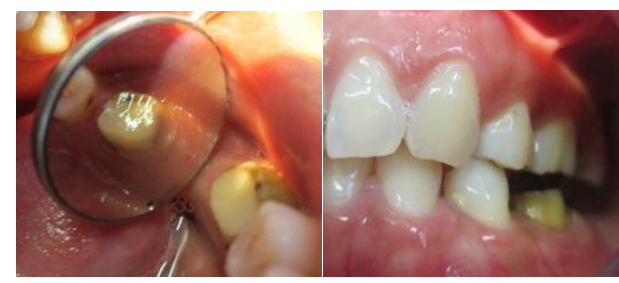

A B

Gambar 8. (A) Hasil preparasi tonggak gigi 36. (B) Pengecekan oklusi 


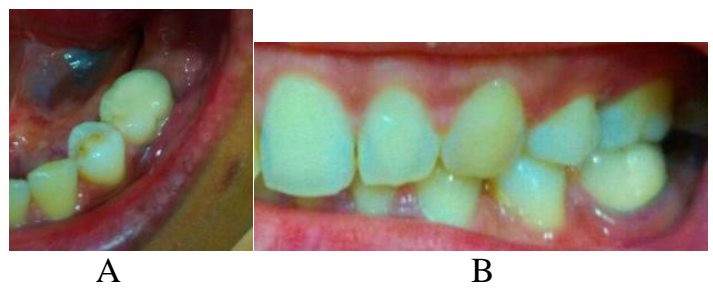

Gambar 13. Gigi 36 (A) Sementasi mahkota tampak oklusal (B) Posisi oklusi sentrik

\section{PEMBAHASAN}

Karies yang cukup luas dan melibatkan tonjol merupakan kontraindikasi restorasi amalgam, karena pada prosedurnya butuh pengurangan jaringan keras gigi yang cukup banyak agar menghasilkan retensi dan resistensi yang baik, dan hal tersebut akan melemahkan struktur gigi tersisa yang dapat menyebabkan fraktur ${ }^{3}$. Pada kasus ini, terjadinya fraktur pada mahkota gigi disebabkan oleh adanya kavitas yang besar namun tetap di restorasi direct dengan amalgam, kasus tersebut sudah masuk ke dalam indikasi restorasi onlay karena sudah melibatkan keempat tonjol. Sehingga bisa dikatakan bahwa kasus ini kontraindikasi untuk dilakukan restorasi amalgam. Meskipun bertahan sampai dengan beberapa tahun, adanya risiko fraktur pada bagian mahkota tidak dapat dihindari.

Adanya restorasi amalgam juga diketahui memegang peranan penting untuk terjadinya penyempitan saluran akar atau obliterasi saluran akar, khususnya bila didahului dengan prosedur mumifikasi sebelumnya ${ }^{4}$. Obliterasi dapat didefinisikan sebagai deposisi jaringan keras ke dalam ruang saluran akar. Faktor-faktor penyebab terjadinya obliterasi saluran akar masih belum jelas, tetapi sebagian besar dihubungkan dengan trauma, umur, iritasi kronis, dan restorasi yang dalam. Respon pulpa terhadap trauma tergantung pada derajat kerusakan neurovaskular, yang salah satu penyebabnya adalah faktor bakteri ${ }^{5}$. Terdapat 3 hal kemungkinan yang akan terjadi, diantaranya penyembuhan pulpa, nekrosis pulpa, dan obliterasi saluran $\mathrm{akar}^{5}$.

Pada kasus ini, penyebab terjadinya obliterasi saluran akar dimungkinkan karena adanya trauma panjang oleh karena karies yang dalam, yang dapat menstimulasi deposisi jaringan keras gigi pada dinding saluran akar sebagai salah satu mekanisme pertahanan oleh pulpa ketika ada karies. Hal tersebut terlihat dari gambaran radiograf dimana pada regio 36 terdapat area radiopak yang meluas sampai dengan dasar kamar pulpa yang disesuaikan dengan kondisi klinis akan adanya restorasi amalgam yang mencapai dasar kamar pulpa, dengan selapis tipis bahan basis berada pada dasarnya.

Berbagai bur dan tip ultrasonik telah dirancang untuk dapat menemukan serta menjangkau ruang pulpa yang mengalami kalsifikasi ${ }^{6}$. Kalsifikasi saluran akar pada kasus ini dapat diatasi dengan penggunaan EDTA gel dan solution pada saat dilakukan negosiasi saluran akar menggunakan File C+. Dalam setiap tahapan preparasi saluran akar yang dilakukan pada kasus ini, penggunaan EDTA gel hampir selalu digunakan dengan tujuan dapat melunakkan dinding dentin saluran akar, baik pada daerah apical maupun koronal.
Hal ini, diperkuat dengan bahasan bahwa penggunaan gel EDTA atau EDTA solution dapat berfungsi untuk melunakkan dentin pada saluran $\mathrm{akar}^{2}$.

EDTA efektif melarutkan bahan anorganik, termasuk hidroksiapatit. Agen chelating biasa digunakan dalam endodontik untuk preparasi saluran akar yag sempit dan terkalsifikasi ${ }^{7}$. Chelation adalah proses fisika-kimia yang mendorong penyerapan ion positif multivalent yang bereaksi dengan ion kalsium yang terkandung dalam hidroksiapatit sehingga menyebabkan perubahan struktur mikro dentin dan perubahan rasio kalsium-fosfor dari permukaan dentin. EDTA merupakan salah satu bahan yang memiliki agen chelating ${ }^{8}$.

EDTA mampu membersihkan dan melebarkan saluran akar, kalsium pada gigi akan diikat oleh EDTA sehingga dentin terkalsifikasi terutama peritubulernya yang membuat dentin lebih mudah diinstrumentasi ${ }^{9}$. Maka dari itu, pada kasus perawatan saluran akar yang memiliki saluran akar yang sempit bahkan buntu seperti kasus di atas, EDTA dapat membantu untuk melunakkan dentin pada dinding saluran akar, sehingga saluran akar dapat diakses kemudian lebih mudah untuk dipreparasi menggunakan instrument preparasi saluran akar.

\section{SIMPULAN DAN SARAN}

Dalam kasus ini, penggunaan EDTA baik sediaan gel maupun solution sangat berperan untuk melunakkan dentin pada dinding saluran akar, sehingga saat dilakukan perawatan saluran akar dapat dicapai panjang kerja yang sesuai dan lebih mudah dipreparasi karena sifat dari EDTA yang merupakan agen chelation.

\section{UCAPAN TERIMA KASIH}

Penulis mengucapkan terima kasih kepada Tuhan Yang Maha Esa, keluarga dan pihak yang telah membantu dalam penyelesaian artikel ini

\section{DAFTAR PUSTAKA}

1. Hulsmann,M., Heckendorf,M., Lennon, A., Chelating Agents in Root Canal Treatment: Mode of Action and Indications for Their Use, A Review, International Endodontic Journal, Vol. 36, 2003, PP 810-830

2. Bernice, Thomas., Manoj, Chandak., Adityavardhan, Patidar., Bharat, Deosarkar., Harshit, Kothari., Calcified Canals - A Review, IOSR Journal of Dental and Medical Sciences, Volume 13, Issue 5 Ver. IV.2014, PP 38-43

3. Robertson TM, Heymann HO, dan Swift EJ, 2006, Sturdevant's Art and Science of Operative Dentistry, $5^{\text {th }}$ ed., North Carolina, Mosby Elsvier

4. Commander Patrick J. Munley, DC, dan Captain Gary G. Goodell. Calcific Metamorphosis, The Journal of The American Dental Association, Vol. 27. No.4, April, 2005.

5. PJ Van der Vyer, F. Paleker, Endodontic and Restorative Management of A Lower Molar With A Calcified Pulp Chamber. SADJ. Vol. 68, No. 10, p450 - p456. November 2013 
6. Shruti. S, Ritu. P, Pratibha. A, Conservative management of Calcified Canal with Maxillary Left Incisor: A Case Report. International Journal of Woman Dentists. Vol. 1 (1) 49-51. 2014.

7. Haapasalo M, Shen Y, Qian W. Irrigation in endodontics. Dent Clin; 2010: 291-296
8. Kalluru RS, Kumar ND, Ahmed S, Sathis ES, Jayaprakash T, Garlpati R, Somwya B, Reddy KN. Comparative evaluation of the effect of EDTA, EDTAC, NaOCL, and MTAD on microhardness of human dentin -an in vitro study. J. Clin Diagn Res; 2014: 8(4): 39.

9. Mohammadi Z., Sodium hypochlorite in endodontics: an update review. Intl Dent J; 2008: 58(6): 330-334. 